
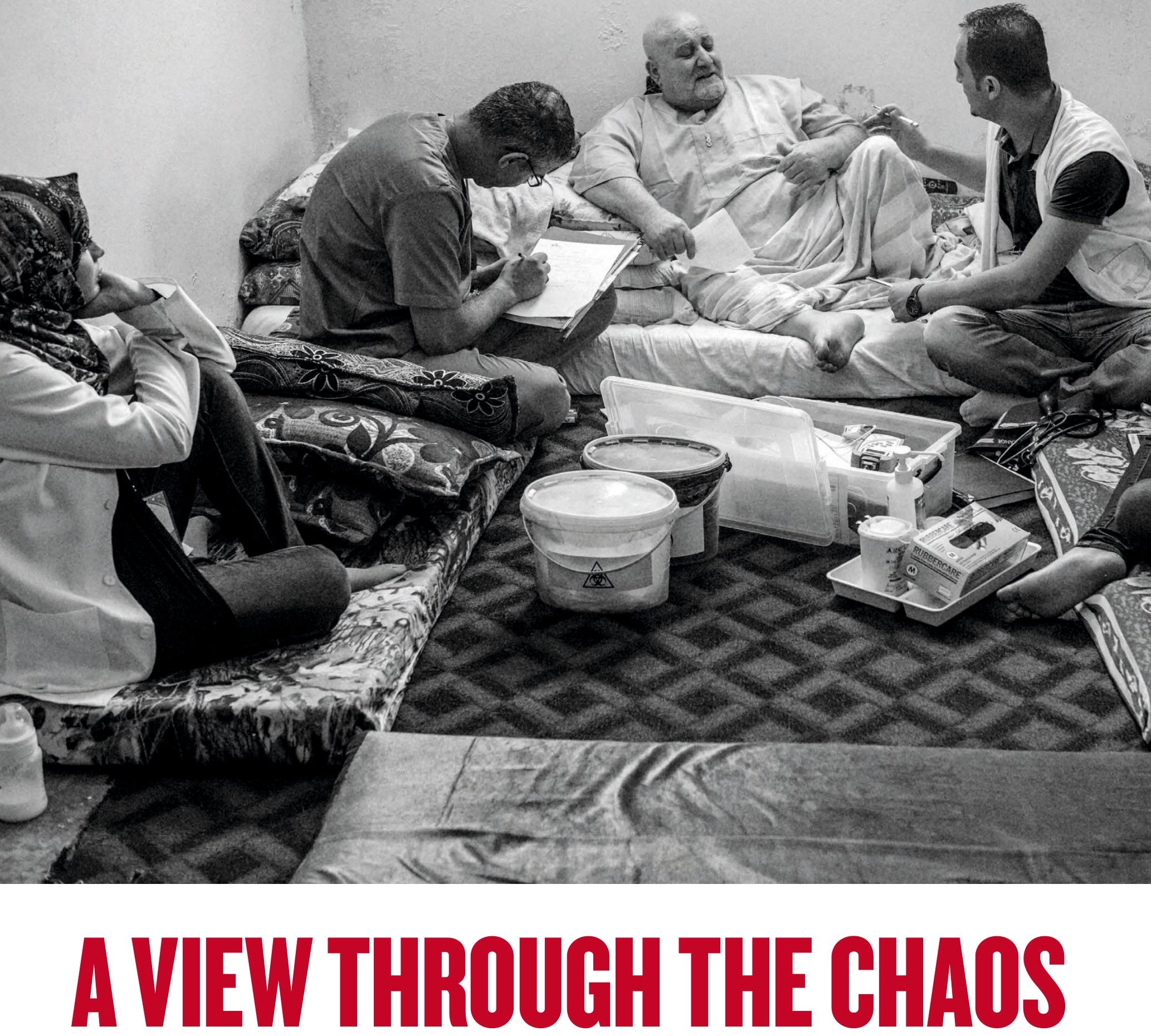

\title{
THE WAR IN SYRIA IS BECOMING A TESTING GROUND FOR MUCH-NEEDED IMPROVEMENTS TO HOW DATA ARE MANAGED IN A CRISIS.
}

\section{By Amy Maxmen}

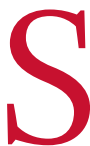
hadows shroud Issam Salim's face as he recounts the operations he's performed. Yesterday, he tended to fractures, mangled limbs and intestinal injuries caused by an explosion from an unknown source. "The situation was very tense," he says. Today, there have been no war-wounded patients, so he saw people with bladder stones and hernias instead. Salim is deputy director of a hospital in southern Syria, and he's talking to an Iraqi surgeon, Ghassan Aziz, through a flickering Skype video call.

Aziz is not far away - just two hours south by car, in Jordan's capital, Amman. It is from here that the organization Aziz works for, Médecins Sans Frontières (MSF), has been providing medical aid to clinics in southern Syria during a conflict that has become one of 


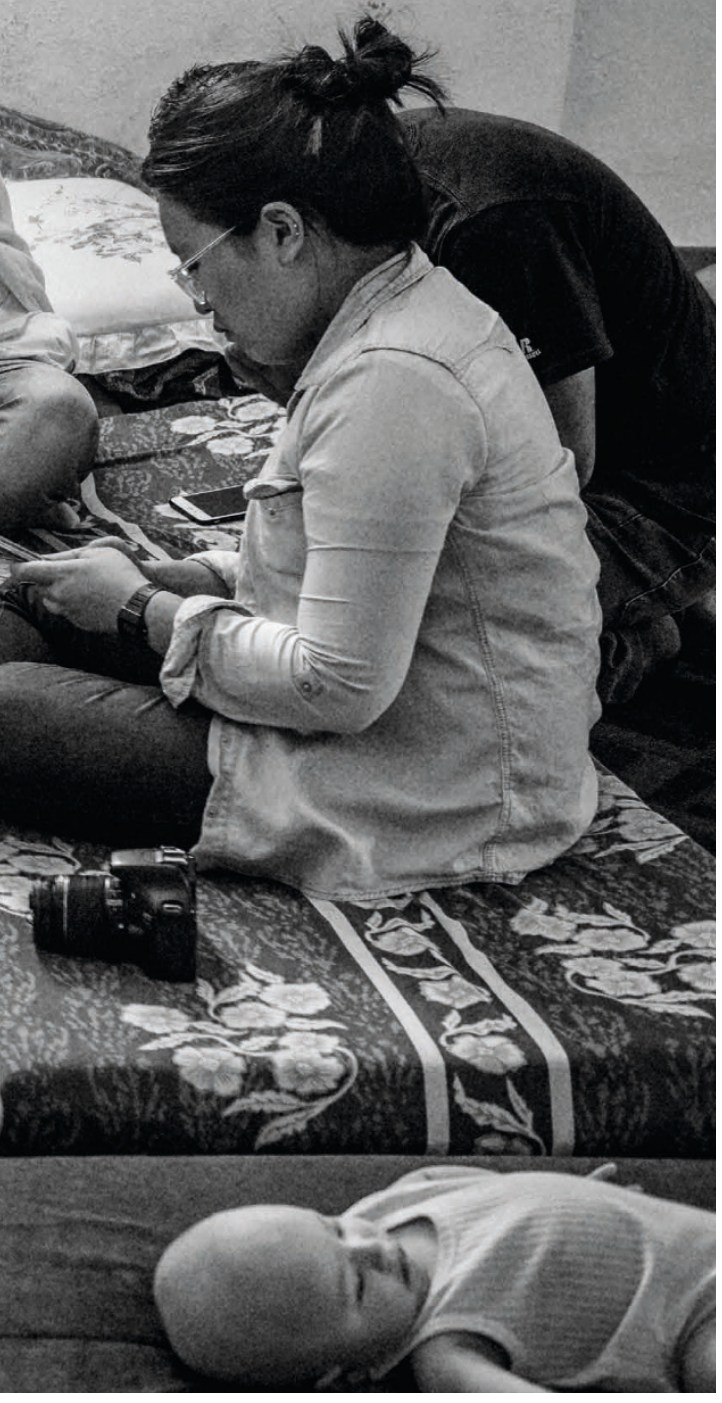

the world's worst ongoing humanitarian crises. But Aziz and his colleagues dare not get much closer. After 13 MSF staff members were kidnapped in January 2014, the organization, also known as Doctors without Borders, pulled its international staff out of the country.

Text messages and calls such as the one with Salim provide a glimpse of what is going on, but it is hardly enough to let MSF staff predict what Syrian doctors and nurses will need most to help their communities. An increase in severe burns might mean that C-4 plastic explosives are in heavy rotation, for example, and therefore medics will require extra antibiotics, intravenous lines and surgical equipment, because they won't have time to sterilize between operations. Or an increase in kidney failures could mean that people with diabetes have lost access to regular care. But the fog of war makes tracking such trends next to impossible.

Whenever war, hurricanes or other disasters ravage part of the globe, one of the biggest problems for aid organizations is a lack of reliable data. People die because front-line responders
A doctor and technicians record health data on a Syrian refugee in Jordan. paper surveys and rigid databases in crisis situations, watching with envy as tech companies expertly mine big data for comparatively mundane purposes.

Three years ago, one frustrated firstresponder decided to do something about it. The result is an innovative piece of software called the Dharma Platform, which almost anyone can use to rapidly collect information and share, analyse and visualize it so that they can act quickly. And although public-health veterans tend to be sceptical of technological fixes, Dharma is winning fans. MSF and other organizations now use it in 22 countries. And so far, the Rise Fund, a 'global impact fund' whose board boasts U2 lead singer Bono, has invested US\$14.3 million in the company behind it.

"I think Dharma is special because it has been developed by people who have worked in these chaotic situations," says Jeremy Farrar, director of biomedical-funding charity the hand-written data into an Excel spreadsheet merged the information with other data, analysed it and generated a report. But the process took five months, and at that point, the results were too old to act on.

In 2015, she worked with MSF during the Ebola crisis in West Africa as the group tried to find a way to track and transmit data on the vital signs of dying patients without a Wi-Fi connection. Berns watched as incredible sums of money were spent. But the outbreak was over before a solution materialized.

She felt broken. "I got burned out after seeing colossal wastes of money and time," she says. "I'd come home and have Uber and Slack, but in the field I had paper and Excel and it was just the ultimate shitshow for data."

Berns complained to her friend Michael Roytman, a data scientist working in Chicago, Illinois, and California's Silicon Valley. Roytman suggested that the two join forces and create software to allow an emergency responder to fill the gap in a flash, without having to ask Excel experts, information-technology departments or consultants for help. The platform also had to work offline, store data securely in the cloud

\section{af I'D COME HOME AND HAVE UBER AND SLACK, BUT IN THE FIELD I HAD PAPER AND EXCEL."}

Wellcome Trust in London, "and it's been roadtested and improved in the midst of reality."

Now, the ultimate trial is in Syria: Salim, whose name has been changed in this story to protect him, started entering patient records into the Dharma Platform in March, and he is looking at health trends even as he shares his data securely with MSF staff in Amman.

It's too soon to say that Dharma has transformed his hospital. And some aid organizations and governments may be reluctant to adopt it. But Aziz, who has deployed Dharma in Iraq, Syria, Jordan and Turkey, is confident that it will usher in a wave of platforms that accelerate evidence-based responses in emergencies, or even in health care generally. "This is like the first version of the iPhone or Yahoo! Messenger," he says. "Maybe something better will come along, but this is the direction we're going in."

\section{BORN OF FRUSTRATION}

Jesse Berns dreamt up Dharma after years of first-hand experience with the injured and ill, first as a helicopter paramedic, and then as a field epidemiologist embedded in some of the world's worst disaster zones. "I've worked in pretty much every conflict since 2006," she says. She became disheartened by the inability to base decisions on data. In 2013, for example, she was surveying the health condition of refugees at the Iraq-Syria border with the World Health Organization. She entered her own and be able to pass information through Bluetooth connections in case bombs, power failures or computer viruses interrupted service. So the pair started a company based in Washington DC to build what was needed in the field.

When they are asked to describe Dharma, Berns and Roytman struggle because there aren't yet many things like it. "It's not a database," says Roytman. "It's a platform or framework that lets people with no technical background create the tool they need."

An early iteration of Dharma caught the attention of Pablo Marco, the head of MSF's Middle East operations, based in Amman, in 2015. His team had been struggling with the complexities of health in the region, which presented challenges MSF was unaccustomed to. For refugees in Africa, he says, the approach is generally straightforward because needs are fairly uniform: provide clean water, food, shelter, antibiotics and vaccines. "We have a checklist," Marco says, "so we can act fast, fast, fast," But refugees from Iraq and Syria have a range of different requirements. They might be managing depression, hypertension or diabetes instead of malnutrition. And their needs are in flux as they move and lose assets, and as access to medicine comes and goes.

Marco wanted to see whether new technology could provide faster feedback. So he asked Berns to meet Aziz, who was preparing to survey some 200,000 Iraqis who had fled south 
from the Islamist terrorist group ISIS in Mosul. Having completed his medical residency in Baghdad amid sectarian violence in 2007, Aziz understood the depth of the challenge before him. Acute traumas would be obvious, but not festering chronic maladies. He readied himself for the undertaking: "You need to train a large number of people to go out to households and fill out paper forms. Then it takes tonnes of time to transfer those forms into Excel, then transfer the data to an analyst and three months go by before they send back findings."

Aziz, a programme manager at MSF's Center for the Advancement of Humanitarian Medicine in Amman, resembles a Silicon Valley techie with his backpack and worn T-shirt, but he has no computer-science background. Sceptical, but willing to give Dharma a try, he downloaded it onto a tablet and built a form with 145 questions. The survey was designed to move fast, asking only questions made relevant by previous responses. Each person would answer a total of about 25 . Women of childbearing age, for example, were asked whether they were pregnant, and children were asked if they had had diarrhoea or asthma attacks in the past two weeks. Iraqi medical students asking the questions sped through the surveys.

By day 5, the students had collected information from 6,455 people. Then Aziz did something he never could have done before. He merged the information from their devices onto his own and he began to interrogate the data, simply by typing in questions: for example, who identifies as head of household (husband, wife, son-in-law, and so on), and what are the chronic illnesses among these household heads? The answers came back instantly, in graph form.

"Even though I had been up since 5 a.m. that day, I stayed awake until 4 a.m. since it was so interesting," he says. In one view, a pie chart revealed that people of various ages and backgrounds were complaining of skin irritation. Within minutes, it was obvious that the burrowing mites that cause scabies had infested mosques, motels and flats in which refugees were living. Aziz shared the data with MSF and in less than six weeks the organization was treating people with scabies and their contacts, and spraying shelters to eradicate the pests. A follow-up survey showed that the rate of scabies had dropped from $72 \%$ to $23 \%$. Without Dharma, Aziz says, it would have taken several months to realize that something so easily fixed needed attention.

He was sold, and went on to use Dharma to survey refugee health in Turkey and Syria. All the while, he kept in touch with Berns, who tweaked the product in response to feedback. The same evolution occurred as the World Health Organization applied Dharma in Iraq, and as the Paris-based aid agency Médecins du Monde piloted it in Lebanon to assess the mental health of Syrian refugees. Preliminary data from that test suggest that refugee women with children have a lower incidence of suicidal thoughts than those without. Now the group is exploring the connection in a larger survey.

As Dharma's use has spread, public-health experts have taken notice. In April, Farrar told Larry Brilliant to check it out. Brilliant is an epidemiologist and former Google executive who now chairs the Skoll Global Threats Fund, a group in San Francisco, California, that identifies solutions to problems imperilling humanity. He was flabbergasted by how simple it was to use. "I am pitched lots and lots of systems that mechanize emergency and publichealth responses, but they take so damn long to learn," he says. "That is not true for Dharma." In July, he joined the company's board.

In Syria, MSF has been anxious to get access to patients' medical records, which would provide a long-term view of how people are faring
"They were finding the wounded and bringing them to clandestine hospitals," Ahmad says. "They weren't even doctors, but they were organized, and I was so touched by their commitment." He gave the couple first-aid kits and training on how to stop bleeding and move the wounded. Then he set out to find doctors said to be operating out of basements, in living rooms and under trees. Underground practices were "mushrooming up everywhere", he recalls.

In 2015, MSF forged a connection with a hospital serving a large population in southern Syria - the one where Salim now works. At first, MSF asked hospital employees to enter patient data into an electronic database that the organization has long deployed around the world. But the Syrians didn't use it. They did not work for MSF, and they had little to

\section{af THIS IS THE ONLY EYE WE HAVE. THIS IS THE ONLY WAY WE CAN TRY TOFORECAST."}

and what support Syrian hospitals need. But that has been next to impossible because hospitals have been targeted by the Syrian regime and terrorist groups. Since March 2011, the non-profit group Physicians for Human Rights in New York City has documented 826 deaths of health-care workers in Syria from targeted bombs, assassinations and torture - more than $90 \%$ by the government.

Although MSF officially withdrew from the country in 2014, it had avoided some dangerous regions since 2011. One afternoon in 2012, Khalid Ahmad, a tropical-medicine doctor with the charity, got an idea about how the group could provide aid in areas that it was unable to reach itself. He was at an MSF office in Turkey, just across the northern Syrian border, when a young Syrian couple approached him. They showed him videos on their phones of people mangled under rubble. gain from entering data into an unfamiliar system. Trying to get meaningful analyses out of it would take training and time, which the overwhelmed hospital staff didn't have. Plus, MSF's internal system is rigid. Requests for changes have to go through technology departments in European cities, a fact that stood out as a bottleneck.

Early this year, Aziz got the green light to try Dharma at the hospital. He designed questionnaires on the platform that mimicked the format of the hand-written record books that hospital staff were accustomed to keeping. Two tablets with the program arrived at the hospital on 1 March, and every day since then, hospital staff have transferred data from hard copies into the devices. Anyone with access to the system can use it to search for trends.

For example, in April, Aziz noticed an unusually high number of infections among women

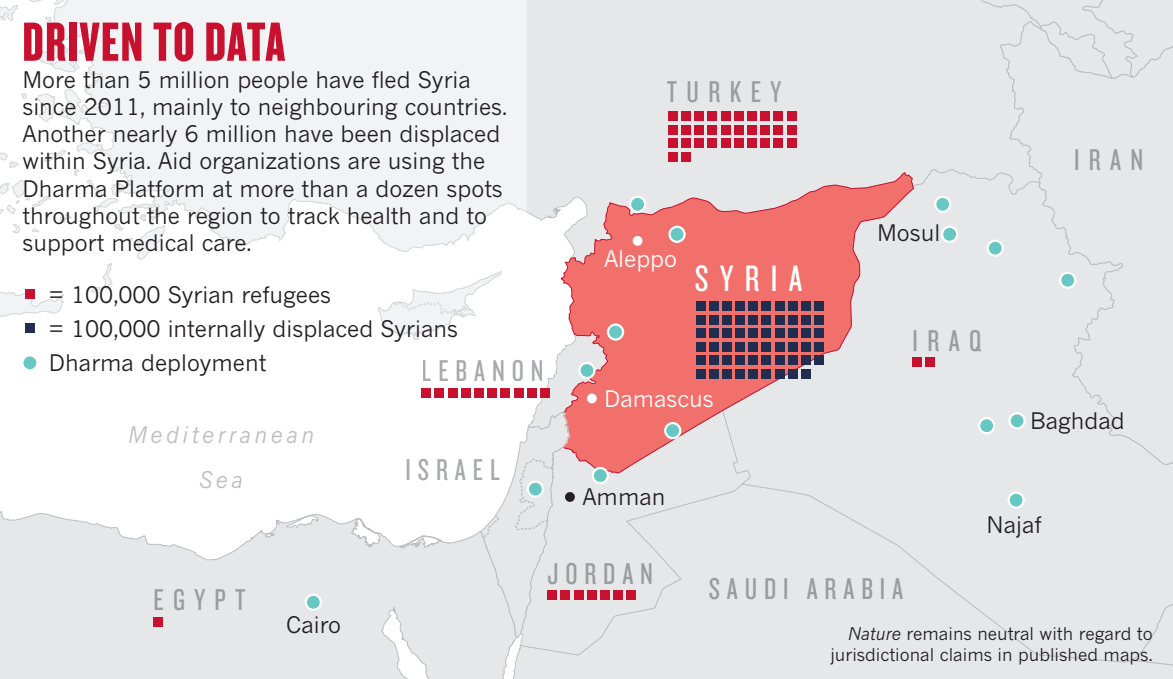


